\title{
The study of the variability of biomass from plants of the Elodea genus from a river in Germany over a period of two hydrological years for investigating their suitability for biogas production
}

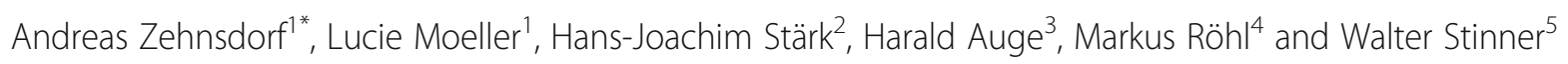

\begin{abstract}
Background: Aquatic plants are an important component of aquatic ecosystems. They are valuable for the oxygen and carbon dioxide household and generate habitats especially for small fish and other small organisms. However, problems for the maintenance of water bodies can result from mass occurrences of these plants. Invasive neophytes - such as members of the Elodea genus - are particularly problematic in this regard. Aquatic plants need to be harvested regularly to ensure that water bodies remain usable and to safeguard flood protection for flowing water bodies. Energy can be produced from the harvested material by anaerobic digestion in biogas plants. Therefore, it is beneficial to know the best time for harvesting in this context.

Methods: To identify the best time for harvesting, samples of the Elodea stock in the river Parthe in LeipzigSchönefeld were taken each week over the course of the two hydrological years 2015 and 2016. The composition of these samples was analyzed in the laboratory. In the second hydrological year, three samples from surface areas of $1 \mathrm{~m}^{2}$ were also harvested once each month in order to determine the biomass yield per unit area.

Results: The best harvesting time for energy production from Elodea biomass in Germany is in the summer months (June to September). During this period, the specific yield of $0.5-0.7 \mathrm{~kg} \mathrm{VS} / \mathrm{m}^{2}$ is relatively high and the Elodea biomass contains the highest fractions of volatile solids ( $80.1 \pm 2.3 \%$ ), high contents of plant nutrients (N $35.9 \pm 4$. $0 \mathrm{~g} / \mathrm{kg}$ TS; P $6.1 \pm 1.4 \mathrm{~g} / \mathrm{kg}$ TS; and $\mathrm{K} 47.7 \pm 8.0 \mathrm{~g} / \mathrm{kg}$ TS$)$, and low concentrations of heavy metals $(\mathrm{Cr} \leq 8.9 \mathrm{mg} / \mathrm{kg}$ TS, $\mathrm{Cd} \leq 0.9 \mathrm{mg} / \mathrm{kg}$ TS, Cu $\leq 120 \mathrm{mg} / \mathrm{kg}$ TS, Ni $\leq 30 \mathrm{mg} / \mathrm{kg}$ TS, Pb $\leq 8.6 \mathrm{mg} / \mathrm{kg}$ TS, and Zn $\leq 439 \mathrm{mg} / \mathrm{kg} \mathrm{TS})$.

Conclusions: Energy production from Elodea biomass is feasible. This biomass also provides the nutrients and trace elements necessary for the digestion in the anaerobic process.
\end{abstract}

Keywords: Elodea nuttallii, Elodea canadensis, Waterweed, Neophyte, Aquatic biomass, Aquatic macrophytes, Hydrological year, Biogas production

\footnotetext{
*Correspondence: andreas.zehnsdorf@ufz.de

${ }^{1}$ Department Centre for Environmental Biotechnology, Helmholtz Centre for

Environmental Research - UFZ, Permoserstrasse 15, 04318 Leipzig, Germany

Full list of author information is available at the end of the article
} 


\section{Background}

Aquatic plants and, in particular, invasive neophytes such as certain members of the Elodea and Myriophyllum genera have the potential to clog up water bodies significantly over the course of one vegetation period. These dense plant stocks are useful hiding places, nursery grounds, and sources of nutrition for aquatic animals such as fish, insects, and mollusks. These fastgrowing plants are reduced by aquatic birds such as the Eurasian coot (Fulica atra L.) or the mute swan (Cygnus olor GMELIN) and by certain fish species such as the common rudd (Scardinius erythrophthalmus L.) [1].

However, the aquatic plant biomass has to be removed at regular intervals to safeguard human interests such as flood protection for flowing water bodies and to allow lakes to be used for leisure purposes. Up to now, the only effective method of accomplishing this has been to cut and remove the plant material [2]. The harvested aquaticplant biomass is generally disposed of without being put to further use, sometimes left to rot on the banks of drainage channels and smaller rivers. The latter approach often has the negative effect that nutrients, which are released when the biomass decomposes, flow back into the water bodies and promote renewed eutrophication.

It is more beneficial to consider the harvested aquaticplant material as a raw material instead of regarding it as a waste that needs to be disposed of. The biomass of Western waterweed (Elodea nuttallii (Planch.) St. John) has already been investigated with regard to its suitability as a raw material for cosmetics [3], as a starting material for hydrothermal carbonization [4] and as a substrate for energy production in biogas plants [5]. Samples of E. nuttallii from five different lakes in Germany showed specific biogas yields of $415-520 \mathrm{~L}_{\text {biogas }} / \mathrm{kg}$ volatile solids [5], which is comparable to hay or cattle dung.

Different requirements apply to aquatic-plant biomass depending on the intended purpose of its subsequent reuse. If this biomass is to be used as a starting material for manufacturing cosmetics, small quantities with high quality are required. For this type of application, it may be advantageous to have divers who can harvest the plants by hand. However, the removal of water plants in order to maintain the usefulness of water bodies generally results in quantities of biomass on a cubic-meter scale within short periods of time. For instance, in the Parthe - a small river in Saxony - about 250 tons of fresh water aquatic-plant biomass was harvested on a length of $7.5 \mathrm{~km}$ in the summer of 2014 [6]. In this case, the primary use that comes into consideration is as a substrate for energy production in biogas plants $[3,5]$. One prerequisite for an efficient use for this purpose are short transport distances to biogas plants - this condition will generally be fulfilled in Germany, which has almost 9000 biogas plants [7]. In addition, the biomass must contain fermentable organic components. Muñoz Escobar et al. [3] observed the biogas production from E. nuttallii samples taken from five lakes in Germany. The specific gas yield was between 415 and $520 \mathrm{~L} / \mathrm{kg}$ volatile solids (VS) in the magnitude of hay or straw.

If the aquatic-plant biomass is to be harvested for some purpose, it is useful to know the extent to which its chemical composition varies over the course of the year. Thus, the aim of this research work was to investigate the physicochemical properties of one Elodea stock in the river Parthe over a period of two hydrological years. This information could then be used to determine the ideal harvesting periods to meet various quality requirements, for example. Although there are many scientific papers about Elodea sp., none of them investigated the seasonal changes in the biomass composition, which are relevant for the use of this aquatic biomass for biogas production.

\section{Methods \\ Sampling}

Samples of the Elodea stock in the river Parthe (a firstorder stream) were taken from the river each week inside Leipzig's city boundaries $\left(51^{\circ} 21^{\prime} 53.2^{\prime \prime} \mathrm{N}, 12^{\circ} 24^{\prime}\right.$ 51.2" E). The river Parthe is $48 \mathrm{~km}$ long; thereof, $12.6 \mathrm{~km}$ is within the city of Leipzig. The area where samples were taken was about $10 \mathrm{~m}$ long, with a river width of around $3 \mathrm{~m}$ and a water depth of between 0.5 and $1 \mathrm{~m}$ (Fig. 1).

The hydrological years (1 November to 31 October, according to the German standard DIN 4049) 2015 and 2016 were used as the period to investigate the material properties of Elodea from the river Parthe in Leipzig, Germany. Samples were taken once a week between 7 a.m. and 10 a.m.

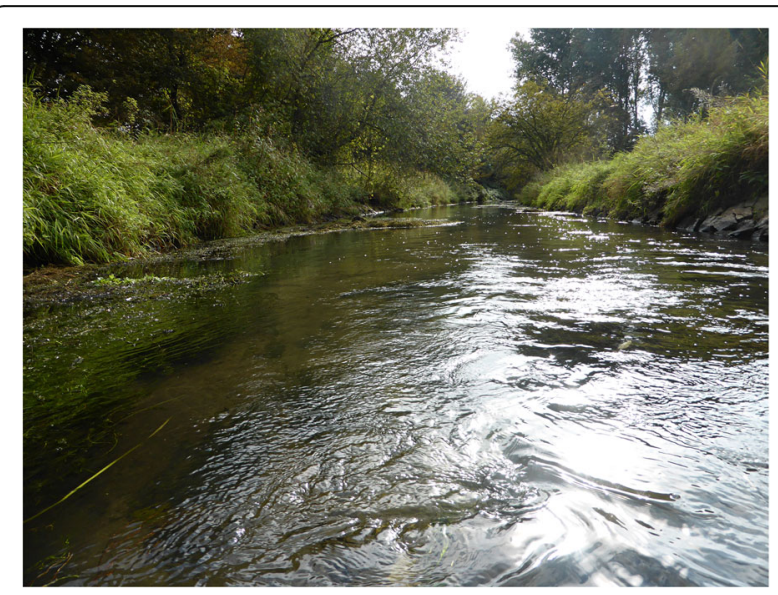

Fig. 1 Area investigated: river Parthe in the city of Leipzig (Saxony, Germany) 
In order to determine the material properties of Elodea biomass, a sample of the Elodea stock was analyzed. The Elodea biomass was harvested using a six-pronged weedremoval device that was attached to a 10-m-long line. If the plants were too fragile to allow for biomass removal using this device, a rake was used instead (23 April 2015 to 15 July 2015). Each sample had a 2-L volume and consisted of above-ground parts of Elodea plants. In order to ensure the homogeneity of the sample, at least two samples were taken and mixed before analysis.

Moreover, the entire aquatic-plant biomass in $1 \mathrm{~m}^{2}$ of surface area of the river Parthe was removed once a month - on 6 June, 12 July, 8 August, 12 September, and 10 October 2016 - and the fresh weight of the removed material was determined in order to calculate the specific yield. A metal frame was used to mark the area in each case (Fig. 2); the weight of the plant biomass was determined using a potato sack and luggage scales. In the case of samples taken in August, September, and October, this procedure was carried out three times to ensure statistical reliability.

The Elodea samples were taken to the laboratory in a closed bucket immediately after being removed. They were then washed with tap water and immediately dried by the use of a paper towel, in order to remove the adhesive water before analysis.

\section{Determination of total and volatile solids}

The fresh samples of Elodea were weighed and dried at $60{ }^{\circ} \mathrm{C}\left(105{ }^{\circ} \mathrm{C}\right.$ would have been too destructive for subsequent analysis) to determine their total solids (TS).

An aliquot of the dried samples was heated to $550{ }^{\circ} \mathrm{C}$ in a muffle furnace to determine the content of volatile solids according to DIN 12879.

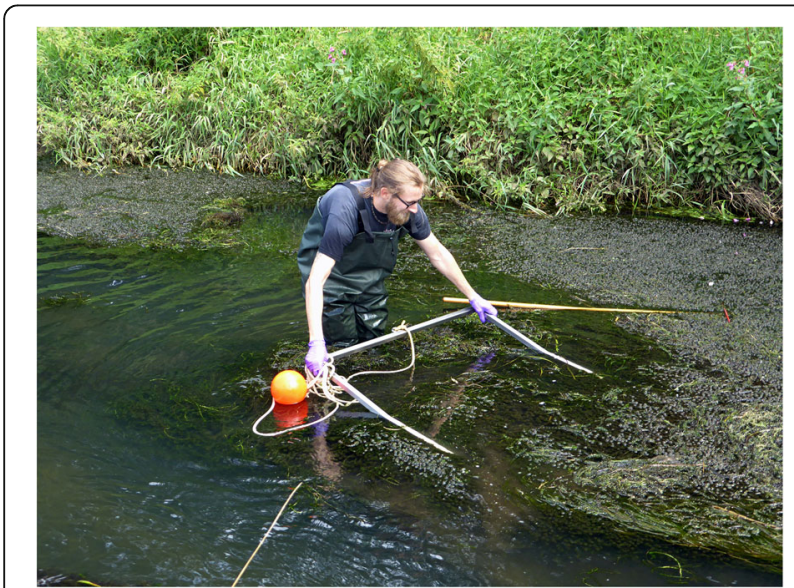

Fig. 2 Harvesting of waterweed with the help of a metal frame of a defined size in order to determine the yield of biomass per square meter

\section{Determination of elements}

The elements aluminum, boron, calcium, iron, potassium, magnesium, manganese, phosphorous, sulfur, and zinc in the plant samples were measured using ICP-OES (ARCOS, SPECTRO Analytical Instruments $\mathrm{GmbH}$, Kleve, Germany) according to the US-EPA method 200.7. The elements arsenic, cadmium, cobalt, chrome, copper, molybdenum, nickel, and lead were measured using ICP-MS (ICAPQs, Thermo Fisher Scientific $\mathrm{GmbH}$, Bremen, Germany) according to the US-EPA method 200.8 due to their lower limit of detection.

\section{Determination of the carbon-nitrogen ratio}

To determine the amounts of carbon and nitrogen contained in the plant samples, they were incinerated at $950{ }^{\circ} \mathrm{C}$ in an element analyzer (Vario-EL III, Elementar Analysensysteme $\mathrm{GmbH}$, Hanau, Germany) with a thermal conductivity detector. The $\mathrm{C} / \mathrm{N}$ ratio was then calculated from the $\mathrm{C}$ and $\mathrm{N}$ contents that were determined.

\section{Results and discussion}

The Elodea stock consisted of around 80\% Elodea canadensis MICHX. and 20\% Elodea nuttallii (PLANCH.) ST. JOHN. The degree of cover fluctuated between approximately $90 \%$ in late summer (Fig. 3) and $10 \%$ in late winter. These two Elodea species native to North America are considered as invasive neophytes in Central Europe [8]. In the river Parthe, they co-existed with Callitriche palustris L. and Ranunculus fluitans LAM.

Figure 4 presents the TS, VS, and the $\mathrm{C} / \mathrm{N}$ ratio of the Elodea biomass as a function of water temperature. The VS - here expressed as a fraction of the TS - is of particular importance for the use of this biomass. The VS exhibits a clear correlation with the water temperature; it increases with increasing water temperature (Fig. 5). VS values of more than $80 \%$ were achieved in 2015 from the start of July to the start of November in 12 of the 53

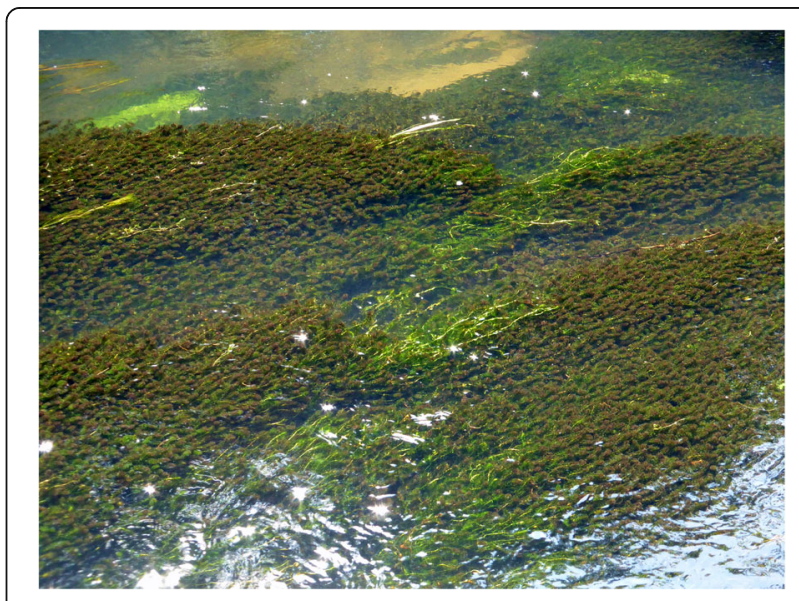

Fig. 3 Waterweed conditions on 6 June 2016 


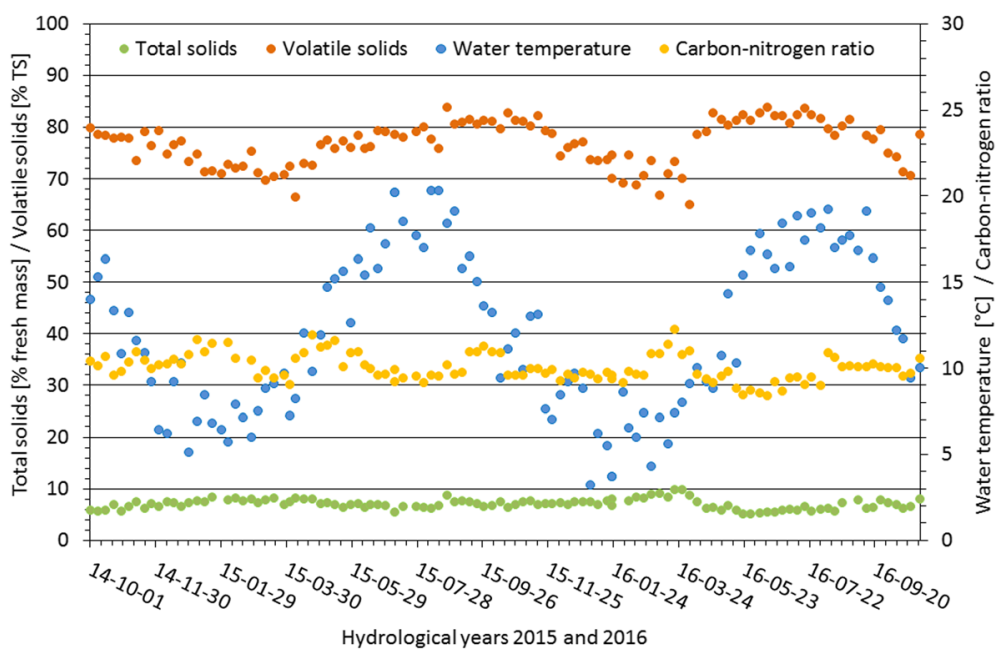

Fig. 4 Total solids (TS), volatile solids (VS), water temperature and carbonnitrogen ratio in the hydrological years 2015 and 2016

samples; the average value was $81.4 \pm 1.0 \%$ at an average water temperature of $14.7 \pm 3.2{ }^{\circ} \mathrm{C}$. In 2016 , the Elodea biomass contained over $80 \%$ VS in 17 of 46 samples between the end of April and the start of September, with an average value of $82.0 \pm 1.0 \%$ and an average water temperature of $15.9 \pm 3.0{ }^{\circ} \mathrm{C}$. A VS value below $70 \%$ was only detected once at the start of March and once at the start of April in $2015(68.1 \pm 2.3 \%$ at an average water temperature of $8.5 \pm 0.4{ }^{\circ} \mathrm{C}$ ). In 2016 , a VS value below $70 \%$ was detected on five occasions $(67.9 \pm 2.0 \%$ at an average water temperature of $\left.6.9 \pm 2.2{ }^{\circ} \mathrm{C}\right)$. The lowest value of the VS during the period of investigation was $64.9 \%$ in April 2016, and the highest value was $83.8 \%$ in August 2015 and June 2016.

The $\mathrm{C} / \mathrm{N}$ ratio was $10.0 \pm 0.8$ on average, which is quite low and corresponds to a $\mathrm{C} / \mathrm{N}$ ratio of vegetable waste [9]. It is therefore recommended to mix the aquatic plant

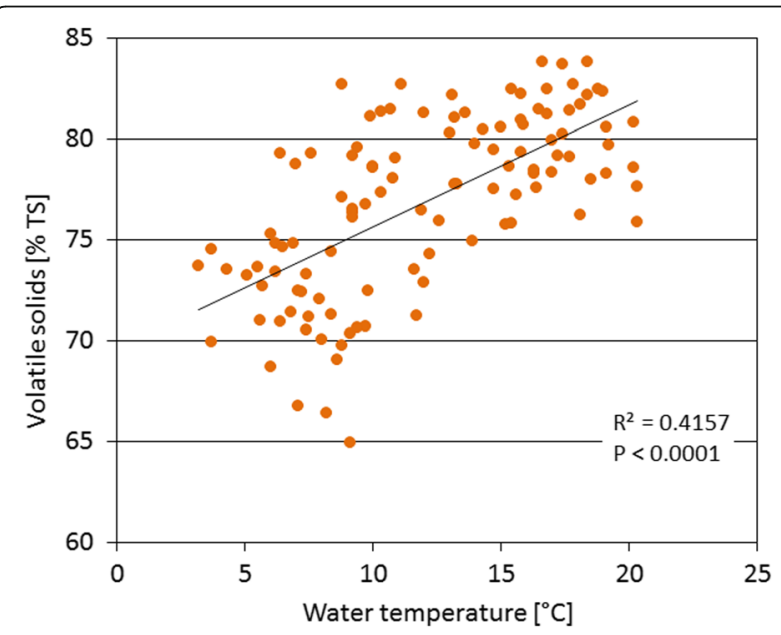

Fig. 5 Volatile solids as a function of water temperature material with a substrate with a high in $\mathrm{C} / \mathrm{N}$ ratio, such as straw for the purposes of AD.

Alongside the VS and $\mathrm{C} / \mathrm{N}$, the yield of aquaticplant biomass per unit area is also of major interest. The results of harvesting the Elodea biomass from surface areas of $1 \mathrm{~m}^{2}$ between June and October 2016 are presented in Table 1 . On average, $11.8 \pm 1.6 \mathrm{~kg}$ of fresh mass per square meter was harvested, with an organic fraction of $78.8 \pm 3.5 \%$ (this corresponds to $0.58 \pm 0.1 \mathrm{~kg}$ of VS per square meter). For the comparison with energy crops, a similar approach was applied for maize from an agricultural field close to Leipzig. In the case of maize, $6.1 \pm 0.6 \mathrm{~kg}$ of fresh mass per square meter and $1.71 \pm 0.2 \mathrm{~kg}$ of VS per square meter were harvested. The harvest of 12 July, which is also presented in Table 1, was carried out around $1 \mathrm{~km}$ downstream as part of a large harvesting measure for the production of silage. This sample is not included in the evaluation above because the water was deeper at this point and the plants had more space to grow. However, it does show that a greater yield per unit area - in this case, $20.6 \mathrm{~kg}$ of fresh mass per square meter - is possible for these aquatic plants with higher water depths.

The water content of the biomass of $93.0 \pm 1.0 \%$ $(n=113)$ on average, which is high in comparison with energy crops such as maize or grain, is useful if a mixed silage of aquatic plants and straw with a suitable dry matter content is created [10]. The TS generation per square meter does not show a clear extension between June and September due to the annual radiation curve. This might be explained by saturated growth. Further research on this topic is necessary.

The concentration of the heavy metals of chrome, lead, nickel, cadmium, and zinc in the biomass falls 
Table 1 Biomass of waterweed in the river Parthe: quantitative determination of biomass growth in an area of $1 \mathrm{~m}^{2}$

\begin{tabular}{llllll}
\hline Date & Fresh mass $\left[\mathrm{kg} / \mathrm{m}^{2}\right]$ & TS $[\% \mathrm{FM}]$ & $\mathrm{TS}\left[\mathrm{kg} / \mathrm{m}^{2}\right]$ & VS $[\% \mathrm{TS}]$ & VS $\left[\mathrm{kg} / \mathrm{m}^{2}\right]$ \\
\hline 06-06-2016 & 12.2 & 5.2 & 0.6 & 82.7 & 0.5 \\
$12-07-2016^{\mathrm{a}, \mathrm{b}}$ & 20.6 & 6.5 & 1.3 & 76.4 & 1.0 \\
$08-08-2016$ & $11.4 \pm 3.0$ & $6.1 \pm 0.0$ & $0.7 \pm 0.2$ & $79.7 \pm 0.1$ & $0.6 \pm 0.1$ \\
$12-09-2016$ & $13.6 \pm 1.5$ & $6.2 \pm 0.0$ & $0.4 \pm 0.1$ & $78.3 \pm 0.2$ & $0.7 \pm 0.1$ \\
$10-10-2016$ & $9.8 \pm 2.5$ & $6.9 \pm 0.1$ & $0.7 \pm 0.2$ & $74.3 \pm 0.2$ & $0.5 \pm 0.1$ \\
\hline
\end{tabular}

TS total solids, VS volatile solids

${ }^{a}$ Only single sampling without repetition (therefore, no standard deviation can be given)

${ }^{b}$ Harvest approx. $1 \mathrm{~km}$ downstream; the water was deeper here, which meant that the plants had more room to grow

with increasing VS fraction (Fig. 6a-e). Otherwise, copper does not show this decrease (Fig. 6f). The decline in heavy metal content with enhancing organic dry weight refers to their concentration in biomass rather than to their absolute content, which is likely to increase with increasing biomass. We assume that even if the same or a higher amount of heavy metals is taken up by the plant, they become "diluted" when the plants grow faster, i.e., produce more organic material, during periods of favorable growing conditions, e.g., at higher temperatures (see Fig. 5).

In contrast to the heavy metals, the elements nitrogen and potassium that are commonly used in fertilizers increased with increasing VS fraction (Fig. 7a, b), while phosphorous remained almost constant (Fig. 7c). Taking into account the observations presented in Figs. 4, 5, 6, and 7 , the summer months between June and September can be identified as the most favorable harvesting period for Elodea biomass for energy production in Germany. The yield per unit area is relatively high during this period (cf. Table 1), and the Elodea biomass contains the highest fractions of VS (cf. Fig. 4), combined with a high content of plant nutrients (cf. Fig. 7) and low concentrations of heavy metals (cf. Fig. 6). This also has a positive effect on the usefulness for fertilizer purposes of the fermentation residues taken from the biogas plant after biogas production. Finally, the elements - such as molybdenum and manganese - that are required for enzymatic reactions in the biogas process are also useful as process-stabilizing components (Fig. 8); however, their proportion in the Elodea biomass is inversely proportional to the VS.

With regard to the concentration of all elements in the aquatic-plant biomass and, in particular, that of heavy
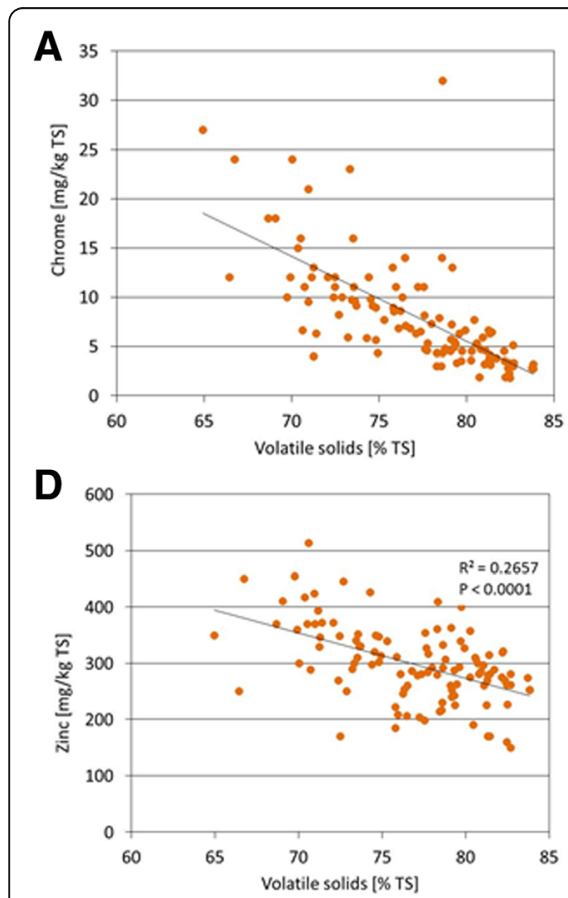

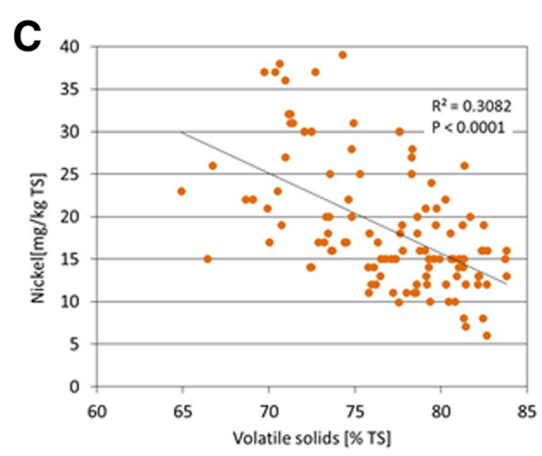

E
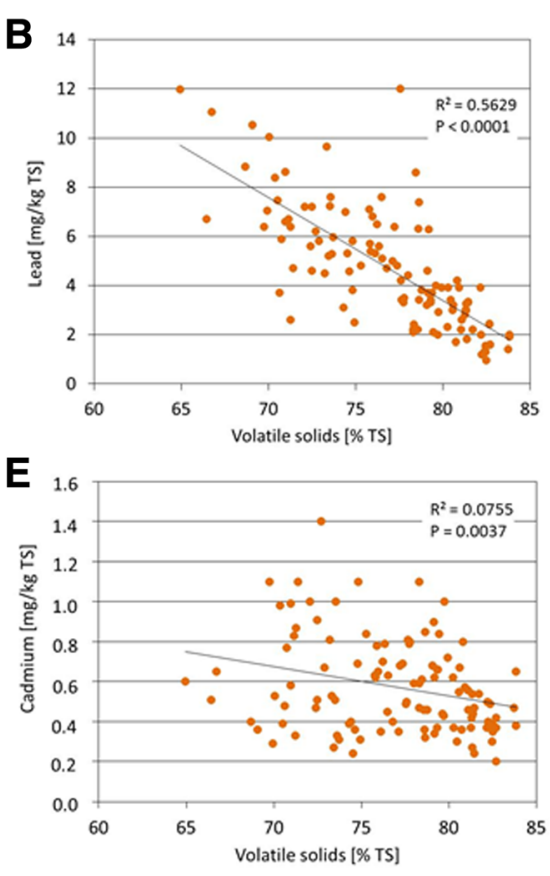

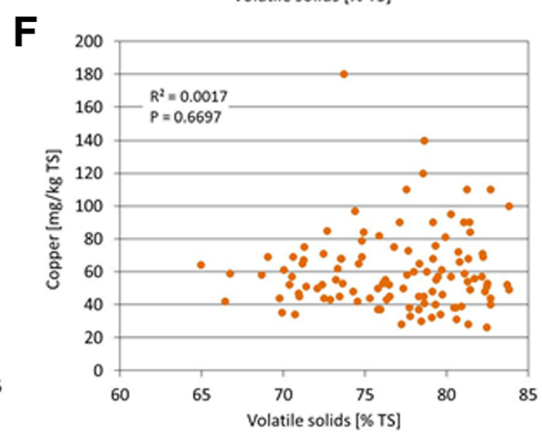

Fig. 6 Concentrations of heavy metals. Concentrations of chrome (a), lead (b), nickel (c), zinc (d), cadmium (e), and copper (f) that are relevant for legal waste and fertilizer requirements as a function of volatile solids 

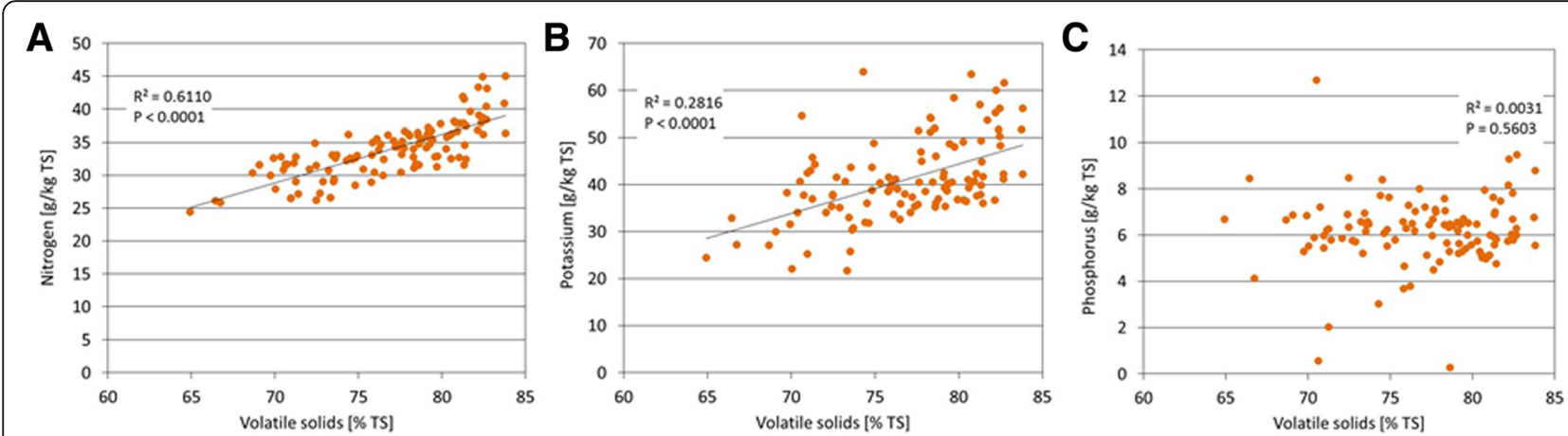

Fig. 7 Concentrations of elements as components of fertilizer. Concentrations of nitrogen (a), potassium (b), and phosphorus (c) as a function of volatile solids

metals, their content in the water and the sediment of the body of water must be taken into account, as there may be very significant regional differences here that are also reflected in the quality of the biomass (cf. [11-13]).

Significant removal of nutrients from the body of water also occurs as a result of the harvesting of aquatic plants [14]. For example, 24.4 $\pm 2.6 \mathrm{~g}$ of nitrogen and $6.5 \pm 2.8 \mathrm{~g}$ of phosphorous per square meter were removed from the river on average by harvesting biomass when determining the yield per unit area.

\section{Conclusions}

Our study shows that biogas production using invasive plant biomass is feasible if based on a season with both optimal yield and chemical composition of plant material. Our approach to harvest highly productive invasive plants for bioenergy production may therefore serve as a model for the economically and environmentally sustainable management of other invasive neophytes. Harvesting Elodea biomass for biogas production may thus not only represent a useful control measure to reduce its ecological and economic impacts but can also even provide an additional economic benefit. Moreover, $E$. canadensis and E. nutallii are invasive neophytes, included in the "Black List" of invasive species to be controlled in Germany [7]. Eradication of wellestablished invasive plants is often not feasible; hence, alternative control measures have to be considered [15]. As biomass production of invasive plants is often high [16, 17], harvesting their biomass, e.g., for bioenergy conversion, has been suggested as an alternative management strategy [18]. This approach, however, may be economically unsustainable if the conversion process depends on the availability and characteristics of the particular plant population [19]. If harvesting is managed in a targeted manner, the removal of aquatic plants to maintain the usefulness of water bodies can be combined with both the harvesting of an innovative substrate for biogas plants and a significant removal of nutrients from the relevant water bodies. Further studies are needed to elucidate how biomass harvests will influence both the longterm dynamics of the invasive plant population and the response of the native species community.
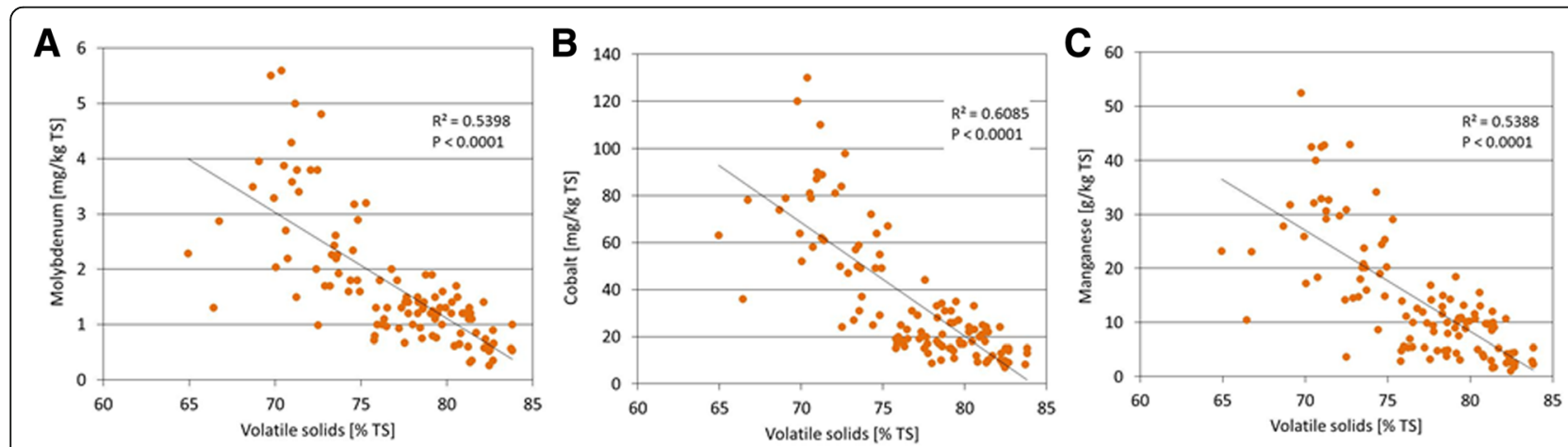

Fig. 8 Concentrations of elements useful for enzymatic processes in the biogas process. Concentrations of molybdenum (a), cobalt (b), and manganese (c) as a function of volatile solids 


\section{Abbreviations}

FM: Fresh mass [kg]; TS: Total solids [\% FM]; VS: Volatile solids [\% TS]

\section{Acknowledgements}

The authors would like to thank Steffen Schmidt, Aline Bauer, Markus Gießmann, Harald Wedwitschka, Sebastian Engel, and Lukas Marx for their support in collecting the samples and carrying out the analysis; Antje Thondorf from the Department of Community Ecology for the analysis of carbon and nitrogen; and Grit Weichert and Ines Richter for their support in the Department Centre for Environmental Biotechnology's laboratory.

\section{Funding}

The investigations that form the basis for this article were carried out within the framework of the "Aquatic macrophytes - Optimal ecological and economic use" (AquaMak) research project. The "AquaMak" project is supported by the German Federal Ministry of Food, Agriculture and Consumer Protection with funds from the so-called Energy and Climate Funds (EKF) on the basis of a decision of the German Parliament (grant number: 22403013). The project partners are the Helmholtz Centre for Environmental Research - UFZ, Nürtingen-Geislingen University - HfWU, and the German Biomass Research Centre - DBFZ.

\section{Authors' contributions}

AZ led the project, collected and sorted the publication and information material, collected and analyzed the samples, and prepared the manuscript. LM collected and analyzed the samples, contributed to the critical reading of the manuscript, and provided input for the final version. HJS analyzed the Elodea samples on elements using ICP-OES and ICP-MS. HA determined the C/N ratio of the Elodea samples. MR and WS contributed to the consultations and critical reading of the manuscript. All authors edited and approved the final manuscript.

\section{Authors' information}

$A Z$ is a senior researcher and group leader of the research group Bioprocess Engineering at the Department Centre for Environmental Biotechnology at the Helmholtz Centre for Environmental Research GmbH - UFZ and professor at the University of Cooperative Education Riesa. LM is a researcher at the Department Centre for Environmental Biotechnology at the Helmholtz Centre for Environmental Research GmbH - UFZ. HJS is a senior researcher in the Department of Analytical Chemistry at the Helmholtz Centre for Environmental Research GmbH - UFZ. HA is a senior researcher and a head of the research group Plant Population Ecology at the Department of Community Ecology at the Helmholtz Centre for Environmental Research GmbH - UFZ. MR is a research assistant at the Institute for Applied Research (IAF) and Institute for Landscape and Environment (ILU) at the Nürtingen-Geislingen University. WS is a senior researcher in the Department of Biochemical Conversion at Deutsches Biomasseforschungszentrum gGmbH - DBFZ.

\section{Competing interests}

The authors declare that they have no competing interests.

\section{Publisher's Note}

Springer Nature remains neutral with regard to jurisdictional claims in published maps and institutional affiliations.

\section{Author details}

${ }^{1}$ Department Centre for Environmental Biotechnology, Helmholtz Centre for Environmental Research - UFZ, Permoserstrasse 15, 04318 Leipzig, Germany. ${ }^{2}$ Department of Analytical Chemistry, Helmholtz Centre for Environmental Research - UFZ, Permoserstrasse 15, 04318 Leipzig, Germany. ${ }^{3}$ Department of Community Ecology, Helmholtz Centre for Environmental Research - UFZ, Theodor-Lieser-Strasse 4, 06120 Halle, Germany. ${ }^{4}$ Institute for Landscape and Environment (ILU), Nürtingen-Geislingen University (HfWU), Sigmaringer Strasse 14, 72622 Nürtingen, Germany. ${ }^{5}$ German Biomass Research Centre DBFZ, Torgauer Strasse 116, 04347 Leipzig, Germany.

Received: 19 January 2017 Accepted: 9 May 2017 Published online: 23 May 2017

\section{References}

1. Podraza $P$, Brinkmann T, Evers $P$, von Felde D, Frost U, Klopp R, Knotte $H$, Kühlmann M, Kuk M, Lipka P, Nusch EA, Stengert M, Wessel M, van de Weyer K
(2008) Untersuchungen zur Massenentwicklung von Wasserpflanzen in den Ruhrstauseen und Gegenmaßnahmen. Final report, research project for the Ministry of Environment and Conservation, Agriculture and Consumer Protection of the Federal State of North Rhine Westphalia (MUNLV).

2. Zehnsdorf A, Hussner A, Eismann F, Rönicke H, Melzer A (2015) Management options of invasive Elodea nuttallii and Elodea canadensis. Limnologica 51:110-117. doi:10.1016/j.limno.2014.12.010

3. Muñoz Escobar M, Voyevoda M, Fühner C, Zehnsdorf A (2011) Potential uses of Elodea nuttallii-harvested biomass. Energy Sustain Soc 1:4. doi:10.1186/2192-0567-1-4

4. Pörschmann J, Weiner B, Wedwitschka H, Zehnsdorf A, Köhler R, Kopinke FD (2015) Characterization of biochars and dissolved organic matter phases obtained upon hydrothermal carbonization of Elodea nuttallii. Bioresour Technol 189:145-153. doi:10.1016/j.biortech.2015.03.146

5. Zehnsdorf A, Korn U, Pröter J, Naumann D, Seirig M, Rönicke H, Pieper B (2011) Western waterweed (Elodea nuttallii) as a co-substrate for biogas plants. Agric Eng 66:136-139

6. Wedwitschka H, Gießmann M, Gallegos D, Rajendran PK, Stinner W (2017) In Mischung konservieren. In: Moeller, Zehnsdorf (Eds.) Wasserpflanzenmanagement. p. 26-31. ISBN 978-3-944280-06-6

7. Fachverband Biogas (2015) Branchenzahlen 2015 und Prognose der Branchenentwicklung 2016. http://www.biogas.org/edcom/webfvb.nsf/id/ DE_Branchenzahlen/\$file/16-09-23_Biogas_Branchenzahlen-2015_Prognose2016.pdf. Accessed 16 May 2017

8. Nehring S, Kowarik I, Rabitsch W, EssI F (2013) Naturschutzfachliche Invasivitätsbewertungen für in Deutschland wild lebende gebietsfremde Gefäßpflanzen. Bundesamt für Naturschutz, Bonn-Bad Godesberg, https:// www.bfn.de/fileadmin/MDB/documents/service/skript352.pdf. Accessed 16 May 2017. ISBN 978-3-89624-087-3

9. Amlinger F, Peyr S, Hildebrandt U, Müsken J, Cuhls C, Clemens J (2005) The state of the art of composting. A guide to good practice. BMLFUW Österreich. https://www.bmlfuw.gv.at/dam/jcr:c5b09547-935a-4f9f-b9d0-2940141b0262/ Richtlinie_20Kompost\%5B1\%5D.pdf Accessed 16 May 2017

10. Wedwitschka H, Stinner W, Moeller L, Roth S, Brummer V, Röhl M, Herbes C, Zehnsdorf A (2016) Wasserpflanzen als Substrat für Biogasanlagen - praxisgerechte Silierung und Vergärung. In: Nelles, M., (Ed.) 10th Rostocker Bioenergieforum on 16th and 17th Juni 2016 of The University of Rostock: Conference proceedings, Fonts Series Umweltingenieurwesen 58, The University of Rostock, Faculty of Agricultural and Environmental Sciences, Rostock, p. 259 - 265

11. Gouder de Beauregard A-C, Mahy G (2002) Phytoremediation of heavy metals: the role of macrophytes in a stormwater basin. Ecohydrol Hydrobiol 2:289-295

12. Hoffmann M, Reader U, Melzer A (2015) Influence of environmental conditions on the regenerative capacity and the survivability of Elodea nuttallii fragments. J Limnol 74:12-20. doi:10.4081/jlimnol.2014.952

13. Maleva MG, Nekrasova GF, Bezel VS (2004) The response of hydrophytes to environmental pollution with heavy metals. Russ J Ecol 35:230-235. doi:10. 1023/B:RUSE.0000033791.94837.9e

14. Robach F, Hajnsek I, Eglin I, Trémolières M (1995) Phosphorous sources for aquatic macrophytes in running waters: water or sediment? Acta bot Gallica 142:719-731, ISSN 1253-8078

15. Myers JH, Simberloff D, Kuris AM, Carey JR (2000) Eradication revisited: dealing with exotic species. Trends Ecol Evol 15:316-320

16. Maron $\mathrm{L}$, Auge H, Pearson DE, Korell L, Hensen I, Suding KN, Stein C (2014) Staged invasions across disparate grasslands: effects of consumers, disturbance and seed provenance on productivity and species richness. Ecol Lett 17:499-507. doi:10.1111/ele.12250

17. Vila M, Espinar JL, Hejda M, Hulme PE, Jarosik V, Maron JL, Pergl J, Schaffner $U$, Sun Y, Pysek P (2011) Ecological impacts of invasive alien plants: a metaanalysis of their effects on species, communities and ecosystems. Ecol Lett 14:702-708. doi:10.1111/j.1461-0248.2011.01628.x

18. Barnes MA, Deines AM, Gentile RM, Grieneisen RE (2014) Adapting to invasions in a changing world: invasive species as an economic resource. In: Ziska LH, Dukes JS (eds) Invasive species and global climate change. CAB International, Wollingford, pp 326-344

19. Nackley LL (2015) Good intentions vs. good ideas: evaluating bioenergy projects that utilize invasive plant feedstock. In: Quinn LD, Matlaga DP, Barney JN (eds) Bioenergy and biological invasions: ecological, agronomic, and policy perspectives on minimizing risk. CAB International, Wollingford, pp 134-154 